\title{
Model for growth and survival of mussels Mytilus edulis reared in Prince Edward Island, Canada
}

\author{
Jean-Sébastien Lauzon-Guay, ${ }^{1, *}$, Myriam A. Barbeau ${ }^{1}$, James Watmough ${ }^{2}$, \\ Diana J. Hamilton ${ }^{1,3}$
}

\author{
${ }^{1}$ Biology Department, University of New Brunswick, Bag Service 45111, Fredericton, New Brunswick E3B 6E1, Canada \\ ${ }^{2}$ Department of Mathematics and Statistics, University of New Brunswick, PO Box 4400, Fredericton, \\ New Brunswick E3B 5A3, Canada \\ ${ }^{3}$ Present address: Department of Biology, Mount Allison University, 63B York Street, Sackville, \\ New Brunswick E4L 1G7, Canada
}

\begin{abstract}
Mathematical models of commercially important species enable one to integrate the diversity of information on these species, understand mechanisms responsible for observed population dynamics, and assess management scenarios. We present a population model for blue mussels Mytilus edulis grown in suspended culture in 2 bays in Prince Edward Island, Canada. The model incorporates a number of ecological processes, namely allometric growth of individual mussels, temperature-dependent growth rates (based on the Lassiter-Kearns equation), and survival of mussels based on self-thinning. Analysis of our model suggests that the optimal temperature for mussel growth is $15.8^{\circ} \mathrm{C}$. Also, survival does not depend on site or year, indicating that self-thinning is probably due to competition for space rather than food or other site-specific conditions. Based on sensitivity analyses, growth predictions are robust to changes in parameter values, while survival predictions are quite sensitive to changes in the strength of the effect of initial mussel density and of self-thinning. Evaluation of management scenarios over one grow-out period indicates that date of deployment strongly affects time for seeds to reach commercial size. Optimal initial mussel density depends on whether one wants to maximise the proportion of mussels surviving to harvest or the number of mussels available at harvest; this decision depends on whether seed availability or lease area is limiting.
\end{abstract}

KEY WORDS: Aquaculture $\cdot$ Blue mussel $\cdot$ Mytilus edulis $\cdot$ Growth $\cdot$ Mathematical model $\cdot$ Survival

\section{INTRODUCTION}

The role of mathematical modelling in understanding the relationship between environmental factors (biotic and abiotic) and population dynamics has long been appreciated (Conway 1977). Modelling can also be a very useful tool for evaluating different management techniques in aquaculture. Models have already been applied to different commercial shellfish species (see Barbeau \& Caswell 1999 for an example for scallops, Gangnery et al. 2003 for oysters, Gangnery et al. 2004 for mussels, and Melià \& Gatto 2005 for clams). Many models have also been developed to describe growth of mussels in aquaculture situations (see Beadman et al. 2002 for review). Such models are often based on an ecophysiological approach and have the advantage of producing very precise results under a wide range of environmental conditions. However, to be accurate, they require a large number of parameters, making them difficult to apply in field conditions and compromising their use in management situations.

Beadman et al. (2002) suggested that modelling of mussel populations should integrate individual processes with the effects of predation, density and food limitation on growth and mortality. Few models have looked directly at sources of mussel mortality, and specific mechanisms to explain mortality are generally omitted. An exception is mortality due to bird predation, which has been modelled on wild mussel beds (Goss-Custard et al. 1995, Hilgerloh \& Siemoneit 1999). Mortality from self-thinning has also been investigated (Fréchette et al. 1996), and some attempts at describing 
self-thinning have been made in both natural (Hughes \& Griffiths 1988) and aquaculture (Fréchette \& Lefaivre 1990, Fréchette et al. 1992) situations.

Blue mussel Mytilus edulis aquaculture is an important part of Atlantic Canada's economy. Over $80 \%$ of the national cultivated mussel crop comes from Prince Edward Island (PEI), Canada. Over the last 10 yr, blue mussel aquaculture has more than quadrupled in PEI (Department of Fisheries and Ocean, Canada, pers. comm). The area available for the establishment of new mussel cultivation leases is rapidly shrinking, and in order for aquaculturists to increase their production, more efficient management techniques need to be developed. Much work has been done to test the effects of different environmental conditions and cultivation techniques on mussel growth and survival (Gosling 1991, Mallet \& Myrand 1995, Lauzon-Guay et al. 2005), but a tool is needed to integrate all of the information and help resource managers and aquaculturists to make informed decisions concerning mussel farming practices.

In this study, we develop a deterministic population model discrete in time and continuous in state (mussel size) that predicts growth and survival of cultivated mussels. Our model, which incorporates a number of ecological processes, consists of 2 sub-models: (1) a growth sub-model based on allometric growth and temperature dependence and (2) a survival submodel based on self-thinning. The parameters of this population model were estimated from field experiments conducted in PEI. We used Monte Carlo simulations to calculate confidence intervals for model predictions based on errors associated with parameter estimates, and we then compared predictions with an independently collected data set. We also conducted a sensitivity analysis to measure the response of the model to small changes in parameter values. Finally, we used the model to evaluate several management scenarios that could optimize growth and survival of cultivated mussels during the grow-out phase.

\section{MATERIALS AND METHODS}

Model structure: growth sub-model. A growth submodel was developed to predict growth in shell length of individual blue mussels Mylitus edulis on 'socks' (plastic mesh sleeves containing mussels, Mallet \& Myrand 1995). It has been shown that mussel growth is size-specific and follows an allometric relationship (Gangnery et al. 2004). Therefore, size-specific daily growth rate of mussels $\left(\mathrm{mm} \mathrm{d}^{-1}\right)$ was modelled by:

$$
G_{\mathrm{opt}}=a L^{b}
$$

where $G_{\text {opt }}=$ daily growth rate $\left(\mathrm{mm} \mathrm{d}^{-1}\right)$ under optimal growing conditions, $a=$ a scale parameter for growth, $b=$ the allometric exponent and $L=$ mussel shell length.

In order to account for seasonal variation in growth, we incorporated temperature dependence into Eq. (1). We chose the equation used first by Lassiter \& Kearns (1974) to model growth rate of phytoplanktonic species, and later by Solidoro et al. (2000) on Tapes philippinarum (Bivalvia) (see Lassiter 1975 for derivation). In their model, optimal growth rate is multiplied by a temperature function described as:

$$
f(T)=\left\{\begin{array}{cc}
\left(\frac{T_{\max }-T}{T_{\max }-T_{\mathrm{opt}}}\right)^{c\left(T_{\max }-T_{\mathrm{opt}}\right)} \mathrm{e}^{c\left(T-T_{\mathrm{opt}}\right)} & T<T_{\max } \\
0 & T \geq T_{\max }
\end{array}\right\}
$$

where $T$ is seawater temperature, $T_{\max }$ is the upper temperature at which growth stops, $T_{\text {opt }}$ is the temperature that maximises growth, and $C$ is a constant related to strength of temperature dependency. This function offers 2 major advantages over more commonly-used functions (e.g. power function, $Q_{10}$ relationship): (1) the exponential factor determines the behaviour of the curves at low temperature, such as would be expected according to Arrhenius's law (Ursin 1967); and (2) the function is valid over a wide range of temperature because it decreases after temperature exceeds an optimal value. The latter is especially important in situations where temperatures above the optimal value are encountered.

Multiplying Eq. (2) by Eq. (1), our growth sub-model becomes:

$$
G_{T}=G_{\text {opt }} f(T)
$$

where $G_{T}$ is temperature-dependent daily growth rate $\left(\mathrm{mm} \mathrm{d}^{-1}\right)$. This growth sub-model predicts growth of individual mussels based on mussel shell length and temperature only, without any density-dependence. Mallet \& Carver (1991) and Lauzon-Guay et al. (2005) demonstrated that growth in terms of shell length of mussels reared on longlines is density-independent over a wide range of mussel densities. With a known temperature $\left(T_{t}\right)$ at time $t$, the shell length of a mussel $(L)$ at time $t+1$ can be calculated using:

$$
L_{t+1}=L_{t}+G_{T}
$$

Model structure: survival sub-model. A survival sub-model was developed based on the self-thinning rule (Westoby 1984). This rule assumes that as individuals grow, competition for space or food increases, forcing the death or dislodgment of some individuals. The self-thinning rule generally takes the form of:

$$
N=\tau M^{\omega}
$$


where $N$ is number of individuals, $\tau$ is density at characteristic mass, $M$ is mean mass of individuals, and $\omega$ is the self-thinning exponent. Many studies have indicated that mussel survival is not dependent on site (Dickie et al. 1984, Mallet \& Carver 1991, Myrand \& Gaudreault 1995, Karayucel \& Karayucel 2000, LauzonGuay et al. 2005), which suggests that a factor constant across sites, such as competition for space, affects survival. When survival is space-driven, we can assume that: (1) the number of mussels $(N)$ is inversely proportional to the space occupied by 1 individual; (2) the surface area of an individual is proportional to the square of one of its linear dimensions (e.g. shell length, $L$ ); and (3) the mass of an individual $(M)$ is proportional the cube of its linear dimension $(L)$. It follows that the number of individuals should be proportional to the mean mass of individuals with an exponent of $-2 / 3$. Therefore, when survival is space-limited, the self-thinning exponent $(\omega)$ should theoretically approach $-2 / 3$. In practice, the self-thinning exponent can vary according to allometric growth (Westoby 1984) or geometry of packing (Hughes \& Griffiths 1988). In our model, we used mean mussel length $\left(L_{t}\right)$ rather than mass for the self-thinning expression, since we followed mussel length rather than mass throughout our field experiments (LauzonGuay et al. 2005). Thus, the expected number of mussels $\left(N \exp _{t}\right)$ remaining on a sock at time $t$ should follow:

$$
N \exp _{t}=\alpha L_{t}^{\beta}
$$

where $\alpha$ is density at characteristic length $(1 \mathrm{~mm})$ and, $\beta$ is the self-thinning exponent. In our model, a value of -2 for $\beta$ would be equivalent to a value of $-2 / 3$ for $\omega$ in Eq. (5) $\left(M \alpha L^{3}\right.$, so $\left.M^{-2 / 3} \alpha L^{-2}\right)$.

We then developed a model to estimate the number of mussels that survive and remain on a sock as a function of the distance between the actual mussel density $\left(N_{t}\right)$ and the expected mussel density $\left(N \exp _{t}\right)$ :

$$
N_{t+1}=\left\{\begin{array}{cc}
\frac{\left(r \kappa N_{t}+N \exp _{t}\right)}{(1+\kappa)} & N_{t}>N \exp _{t} \\
r N_{t} & N_{t}<N \exp _{t}
\end{array}\right\}
$$

where $r$ is survival rate independent of self-thinning and $\kappa$ controls the rate at which $N_{t}$ approaches $N \operatorname{Nexp}_{t}$. When mussel density is below the expected density, self-thinning does not occur and mussels survive at rate $r$.

Experimental data. The data used for model calibration and validation were obtained from field experiments conducted in 2 bays on the north shore of PEI, over a period of 24 mo. Field experiments were of 2 types: (1) small-scale experiments that monitored growth trajectories of individual mussels; and (2) large-scale experiments that monitored populations of socked mussels (Lauzon-Guay et al. 2005).
Growth trajectories of individual mussels. Growth measurements were done on individual mussels glued onto strips of screening mesh, which were hung at 2 commercial mussel farms in St. Peter's Bay $\left(46^{\circ} 25^{\prime} 16^{\prime \prime} \mathrm{N}, 62^{\circ} 37^{\prime} 19^{\prime \prime} \mathrm{W}\right)$ and New London Bay $\left(46^{\circ} 29^{\prime} 34^{\prime \prime} \mathrm{N}, 63^{\circ} 27^{\prime} 05^{\prime \prime} \mathrm{W}\right)$ on the north shore of PEI. Mesh strips measuring $1.5 \mathrm{~m} \times 5 \mathrm{~cm}$ were attached on longlines and weighted at the bottom in order to keep them in a vertical position. Using marine epoxy, a total of 20 mussels (10 on each side) of various shell lengths ( 5 to $50 \mathrm{~mm}$ ) were glued onto the mesh at 10 to $15 \mathrm{~cm}$ intervals. To assure that the same mussels were remeasured at each sampling date, each mussel was numbered using a plastic tag glued onto the shell with Crazy Glue ${ }^{\mathrm{TM}}$. An initial set of 6 mesh strips was hung at each site on 30 to 31 May 2002. These mussels were measured on 3 July, 31 July and 23 September 2002. A second set of 6 mesh strips was deployed between 1 and 8 October 2002, and a third set between 1 and 4 November 2002 at each site. These latter 2 sets were measured at each site on 11 May, 27 June and 14 August 2003. During each sampling period, mussel shell length was measured underwater using plastic calipers. Only live mussels were measured; cracked or empty shells were discarded $(\sim 50 \%)$. Water temperature was measured hourly using underwater-automated temperature recorders (Hugrun ${ }^{\mathrm{TM}}$ ), which were replaced every 6 mo.

Experimental populations of mussels. Experimental mussel aquaculture leases were set up in New London Bay and St. Peter's Bay, PEI, in November 2001 and October 2002. Initially 3 seed sizes of mussels ( 13, 20 and $25 \mathrm{~mm}$ in shell length) were packed into different socks. Each of the 3 seed sizes was packed at a low and a high initial density (ranging from 100 to 800 mussels per $30 \mathrm{~cm}^{2}$ of sock), giving a total of 6 treatments. Growth and survival of mussels on these socks were monitored over a period of 18 mo for socks deployed in 2001, and for 8 mo for socks deployed in 2002. A detailed description of the sites, treatments, sampling protocol and results is given in Lauzon-Guay et al. (2005).

Model calibration: growth sub-model. Parameter estimation of the growth sub-model was done using data from the small-scale experiments on growth trajectories of individual mussels. Hourly data on water temperature were averaged to obtain mean daily water temperatures, which varied between -1 and $24^{\circ} \mathrm{C}$. Data were pooled over both sites for the model calibration. The shell length of each mussel at each sampling period was predicted by numerical simulation of Eq. (4) using SIMULINK and MATLAB (The MathWorks). Squared deviations between the predicted shell length at the end of each interval and the observed shell length were calculated for each mussel 
measurement. The total squared deviation was then obtained by summing the squared deviations over all the mussel measurements. Best parameter estimates were calculated using an optimization procedure based on the simplex (Nelder-Mead) method (Mathews \& Fink 2004) to minimize the total squared deviation. Because of a lack of convergence, $T_{\max }$ was fixed at $30^{\circ} \mathrm{C}$, which is a good estimate of the upper temperature limit for Mytilus edulis (Read \& Cumming 1967, Almada-Villela et al. 1982). We used a wide range of initial parameter values in the optimization and obtained identical results each time.

Confidence intervals of parameter estimates were calculated by bootstrap by redrawing individual mussel length (Manly 1997). A total of 200 bootstrap samples were taken; this number of samples generally produces good estimates (see Manly 1997 for discussion).

Model calibration: survival sub-model. Mussel density on socks at each sampling period was predicted by numerical simulation of Eq. (7) using MATLAB. Squared deviations between the predicted mussel density and the observed mussel density were calculated at each sampling period and for socks of different treatments (i.e. the 3 seed sizes and 2 initial densities, Lauzon-Guay et al. 2005). The total squared deviation was then obtained by summing the squared deviations over all socks and time. Best parameter estimates were calculated using the optimization procedure described above. Only data collected from the large-scale field experiment of 2001 at both sites were used to estimate parameter values and associated standard errors.

Model validation: growth sub-model. To validate the growth sub-model, we compared model predictions to experimental data obtained independently of the data used to parameterise and calibrate the model. Specifically, we compared predictions of mean mussel length for socks of each treatment with observed values recorded on experimental socks. This was done for 2 sites during 2 consecutive years using site- and yearspecific temperature data, and by setting initial seed size as an initial condition of the model. Thus, predictions of the growth sub-model were compared to observed values for a total of 24 combinations of year $\times$ site $\times$ treatment, and an $r^{2}$ value was calculated for each combination.

Model calibration: survival sub-model. To validate the survival sub-model, we compared predictions of mussel densities on socks to observed densities from the large-scale experiment of 2002. This is a data set that is independent of that used to parameterise and calibrate the sub-model. Correspondence between the expected and predicted densities observed was evaluated by $\mathrm{r}^{2}$.

Uncertainty analysis. Each parameter entering the model was calculated with a degree of uncertainty.
This uncertainty resulted in some level of uncertainty in the model predictions. In order to evaluate confidence intervals for the model predictions, an uncertainty analysis was performed using Monte Carlo simulations. For each simulation, parameter values were randomly chosen from the Gaussian probability distributions (Evans et al. 2000) associated with each parameter. Specific probability distributions were calculated for each parameter independently using their mean and standard error obtained by bootstrap (for the growth sub-model) and by linear regression (for the survival sub-model). Also, because of uncertainties in the actual initial conditions (mussel length and density), initial conditions were also randomly chosen from their respective probability distributions. A total of 1000 simulations were done for each sub-model and $95 \%$ confidence intervals were calculated by the percentile method (Manly 1997). We did not consider possible cross-correlations between parameters; our confidence intervals are thus conservative.

Elasticity analysis. Elasticity analysis is a type of sensitivity analysis that uses small proportional perturbations to measure the response of the model to changes in parameter values (Caswell 2001). It generates valuable information on the robustness of the model predictions and helps to identify influential parameters that need to be estimated with more care. Elasticities of mussel size at Day 365 (mean mussel shell length) to $a, b, c, T_{\max }$ and $T_{\text {opt }}$ were calculated numerically by increasing each parameter, one at a time, by $1 \%$ at the beginning of a simulation. Elasticities of the mussel

Table 1. Mytilus edulis. Estimate and standard error (SE) of parameters in population model of cultivated mussels at Prince Edward Island, Canada

\begin{tabular}{|c|c|c|}
\hline $\begin{array}{l}\text { Sub-model } \\
\text { Parameter }\end{array}$ & Value & $\mathrm{SE}$ \\
\hline $\begin{array}{l}\text { Growth (Eqs. } 1 \text { \& 2) } \\
\text { a (scale for growth) }\end{array}$ & 1.14 & 0.01 \\
\hline$b$ (allometric exponent) & -0.547 & 0.002 \\
\hline $\begin{array}{l}C \text { (constant related to } \\
\text { temperature dependency) }\end{array}$ & 0.393 & 0.001 \\
\hline $\begin{array}{l}T_{\max } \text { (upper temperature at } \\
\text { which growth ceases) }\end{array}$ & 30.0 & - \\
\hline $\begin{array}{l}T_{\text {opt }} \text { (temperature maximising } \\
\text { growth) }\end{array}$ & 15.80 & 0.02 \\
\hline $\begin{array}{l}\text { Survival (Eqs. } 6 \text { \& 7) } \\
\alpha \text { (density at } \\
\quad \text { characteristic length) }\end{array}$ & $6.0 \times 10^{5}$ & $0.1 \times 10^{5}$ \\
\hline$\beta$ (self-thinning exponent) & -2.05 & 0.01 \\
\hline $\begin{array}{l}\kappa \text { (constant related to self- } \\
\text { thinning dependency) }\end{array}$ & 0.67 & 0.04 \\
\hline $\begin{array}{l}r \text { (survival rate independent } \\
\text { of self-thinning) }\end{array}$ & 0.9994 & 0.0001 \\
\hline
\end{tabular}


density at harvest (number of mussels on a $30 \mathrm{~cm}$ section of sock) to $\alpha, \beta, \kappa$ and $r$ were also calculated. Elasticity was defined as:

$$
E_{p}=\frac{X_{p}-X_{0}}{X_{0}} \times 100
$$

where $E_{p}(\%)$ is elasticity of the output to a $1 \%$ increase in parameter $p, X_{0}$ is the output of the original model, and $X_{p}$ is the output of the model modified for parameter $p$ (Barbeau \& Caswell 1999).

Evaluation of aquaculture practices. The optimal seeding time, defined as the seeding time that mini-
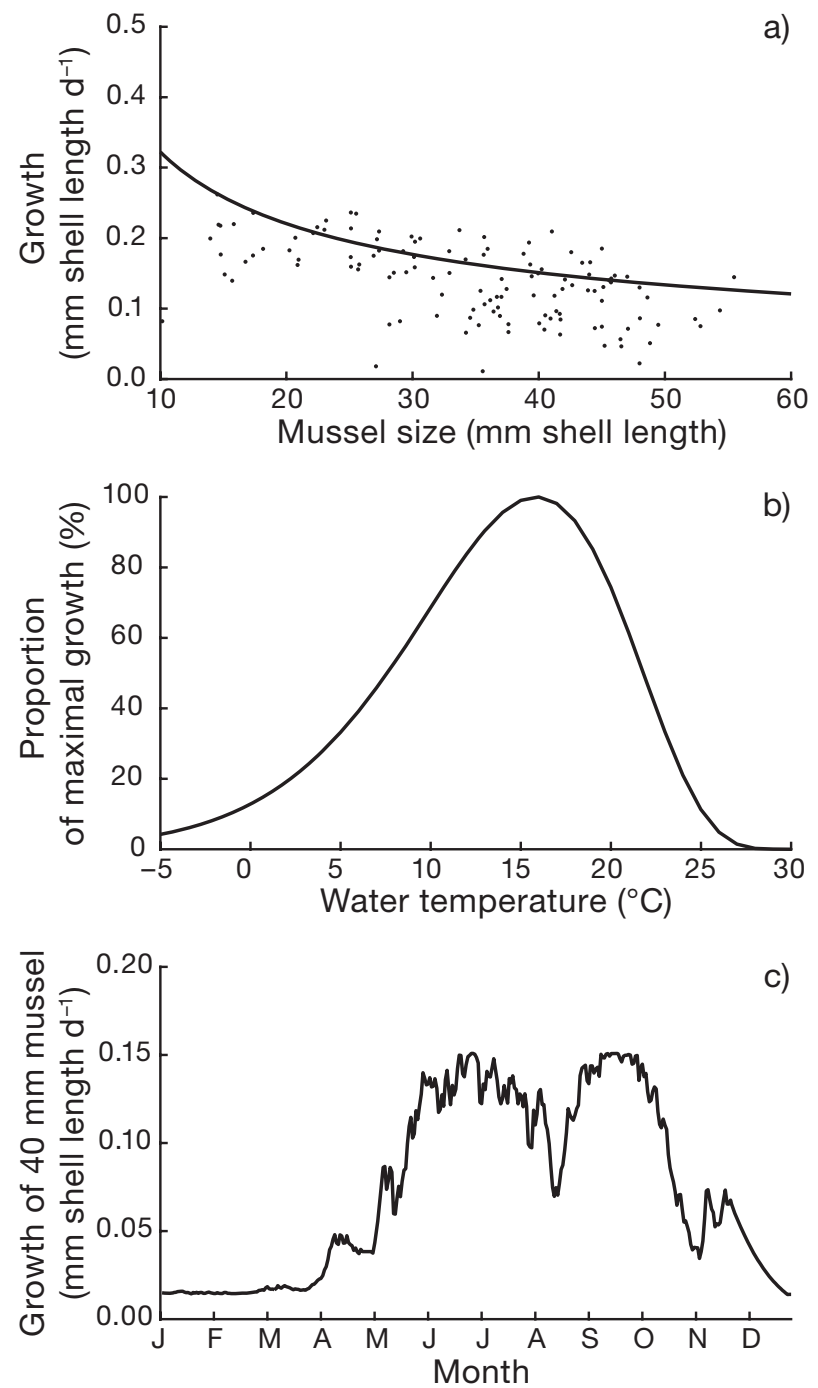

Fig. 1. Mytilus edulis. Mussel growth according to predictions of the growth sub-model as a function of (a) mussel size (line; growth at optimal temperature, $T_{\text {opt }}$ ) and (b) water temperature; data points dots in (a) are observed growth of individual mussels from small-scale experiment in St. Peter's Bay, Prince Edward Island, Canada, in 2002 adjusted for temperature using Eq. (3), and are presented as a visualisation of growth sub-model calibration. (c) Predicted growth profile of a $40 \mathrm{~mm}$ mussel throughout a year mized the grow-out period, was determined by calculating the number of days needed for mussels to reach commercial size (60 mm shell length). A total of 365 simulations were done, 1 for each day of the year being used as the initial condition. For each simulation, 3 mussel sizes were used as initial conditions (15, 20 and $25 \mathrm{~mm}$ in shell length), which represent approximately the size classes of seeds used by aquaculturists.

We used 2 types of optimal seeding density: an optimal density to maximise survival and an optimal density to maximise harvest. The optimal density to maximise survival is the value of $N_{\text {ini }}$ which maximises $N_{\text {har }} / N_{\text {ini }}$ where $N_{\text {ini }}$ is the initial number of mussels and $N_{\text {har }}$ is the number remaining in a sock at harvest time. The optimal density to maximise harvest is the value of $N_{\text {ini }}$ which maximises $N_{\text {har }}$.

\section{RESULTS}

\section{Parameter estimation}

Parameters for the growth sub-model (Table 1) were obtained by fitting Eq. (4) to data collected during the small-scale experiments on growth trajectories of individual mussels (Fig. 1a). The parameterised model explained over $96 \%$ of the variance in growth trajectories. In a similar model applied to Mytilus galloprovincialis, a value of -0.45 was obtained for the allometric exponent (A. Gangnery pers. comm.; aline.gangnery@ifremer.fr). Although slightly smaller than our estimate of $b(-0.547)$, both values produced qualitatively similar growth rates that decreased with increasing mussel size (Fig. 1a).

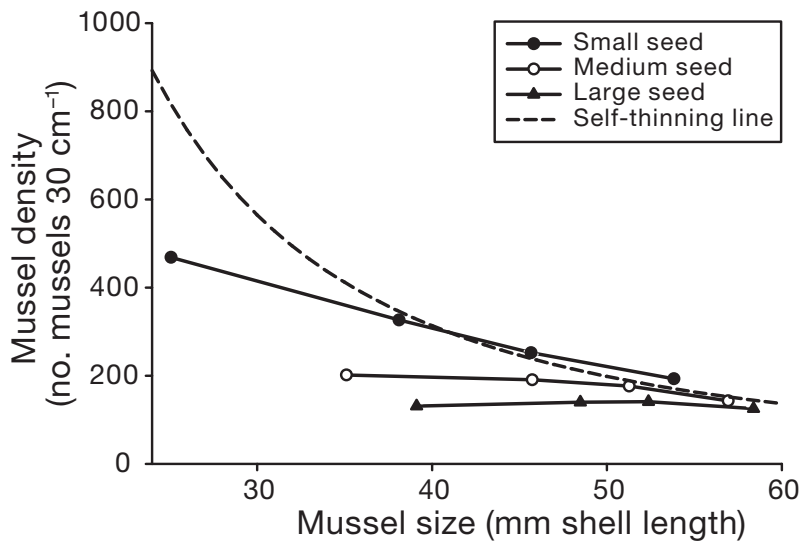

Fig. 2. Mytilus edulis. Self-thinning relationship (Eq. 6) and mean trajectories of mussels density as they increase in shell length, observed in large-scale experiment in St. Peter's Bay in 2001 for small, medium and large seeds at high initial density. Trajectories presented as a visualization of survival submodel calibration 

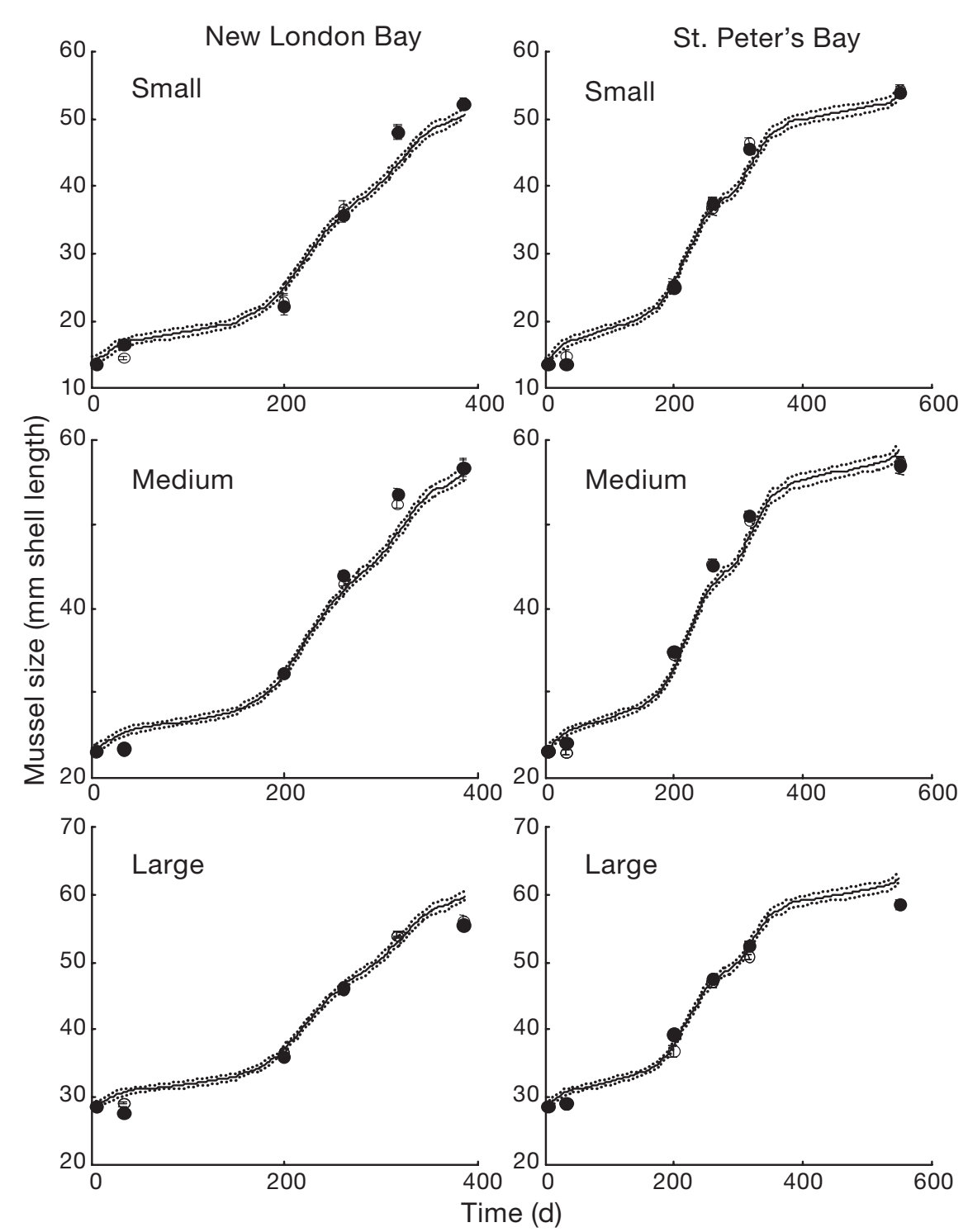

Fig. 3. Mytilus edulis. Validation of the growth sub-model for mussels deployed in November 2001. Simulated (continuous line) and observed (data points) mussel size (mean mussel length on a sock, i.e. plastic mesh sleeve) over time. Mussels were deployed at 3 seed sizes (small, medium and large) and at 2 initial densities (O: low density; 0 : high density) off 2 sites in Prince Edward

Island in 2001. Dotted lines: $95 \%$ confidence intervals of model prediction; Day 0: time at which mussels were deployed

Parameters for the survival sub-model (Table 1) were obtained by fitting Eq. (7) to data collected in 2001. The survival sub-model explained $83 \%$ of the variance in mussel density for the parameter estimation from 2001 data. Fig. 2 shows the self-thinning relationship described by Eq. (6) as well as observed trajectories of mussel density as they increase in shell length. As mussels increase in shell length, their densities converge toward the self-thinning line (Fig. 2). Our estimate of $\beta(-2.05)$ is very similar to the exponent of -2 expected from the selfthinning rule (Westoby 1984). Our daily survival rate $(r)$ translates into a yearly survival rate of $\sim 81 \%\left(r^{365}\right)$.

\section{Temperature effects on growth}

Eq. (2) describes a skewed bell-shaped relationship between growth rate and temperature (Fig. 1b). The best fit for the growth sub-model was obtained by using a value of $15.80^{\circ} \mathrm{C}$ as the optimal temperature $\left(T_{\text {opt }}\right)$. The parameterised growth model produced a seasonal growth profile, with 2 peaks in growth, 1 in spring and 1 in early fall (Fig. 1c). Growth rates drop during both the summer and winter months when the temperature is above and below $T_{\text {opt }}$. Even during the coldest months of winter, when bays are covered in ice, 

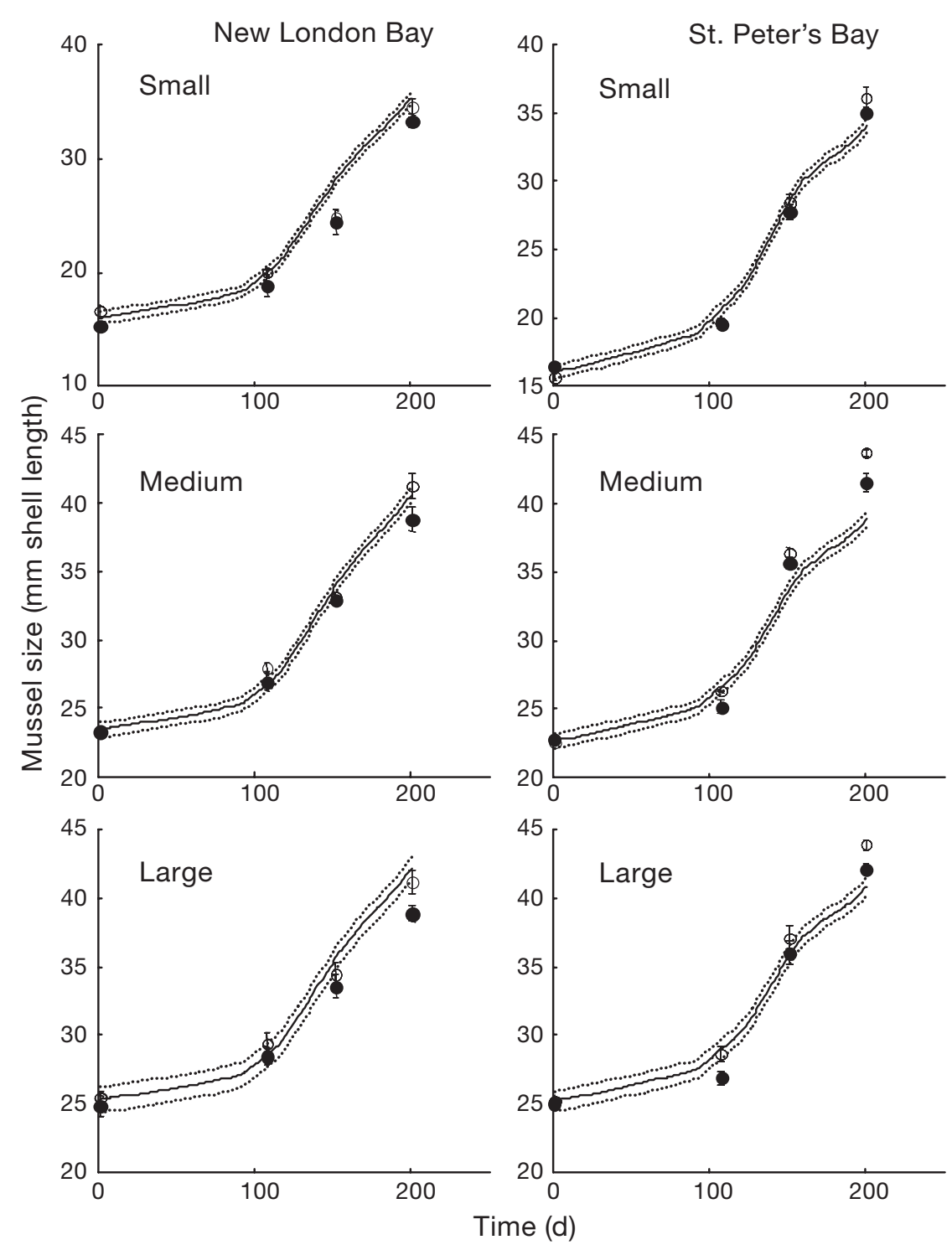

Fig. 4. Mytilus edulis. Validation of the growth sub-model for mussels deployed in October 2002 and first sampled in January 2003 (Day 0). Details as in Fig. 3

field observations indicate that mussels continued to grow at very slow rates.

\section{Comparisons of predicted and observed data: growth sub-model}

There was excellent agreement between predicted mussel sizes and those observed from the large-scale experiments of 2001 (Fig. 3). This fit was equally good for all treatments, with $\mathrm{r}^{2}$ values between 0.93 and 0.99. However, when the model simulations were compared with the results of the large-scale experiment of 2002, the model overestimated growth between the start of the experiment (October 2002) and the first sampling time (January 2003) at both sites. Slow growth is to be expected immediately following deployment, as mussels spend much energy migrating outside the socks and forming new byssal threads. If the model is started using as initial conditions the first sampling time (when the effect of deployment is no longer important), then there is good fit between model predictions and observed data (Fig. 4). This fit was good for all treatments in St. Peter's Bay $\left(r^{2}=0.81\right.$ to 0.98$)$ and in New London Bay $\left(\mathrm{r}^{2}=0.55\right.$ to 0.95$)$.

Overall, growth rates predicted by the growth submodel are in agreement with growth rates observed elsewhere in suspended culture conditions (Mallet \& Carver 1993). The temporal pattern of growth pre- 


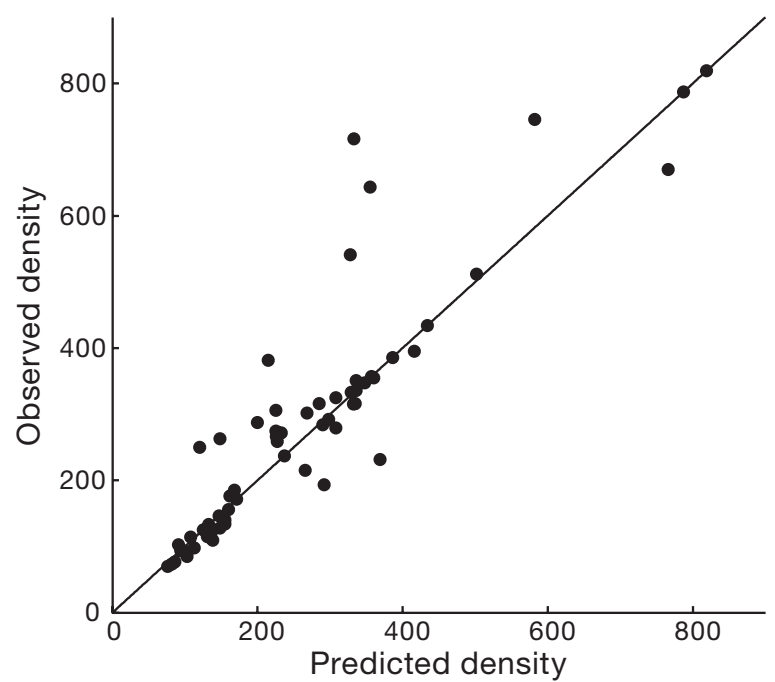

Fig. 5. Mytilus edulis. Validation of survival sub-model. Observed versus predicted density of mussels on $30 \mathrm{~cm} \mathrm{sec-}$ tion of socks deployed in New London Bay and St. Peter's Bay in 2002. Line represents the 1:1 slope

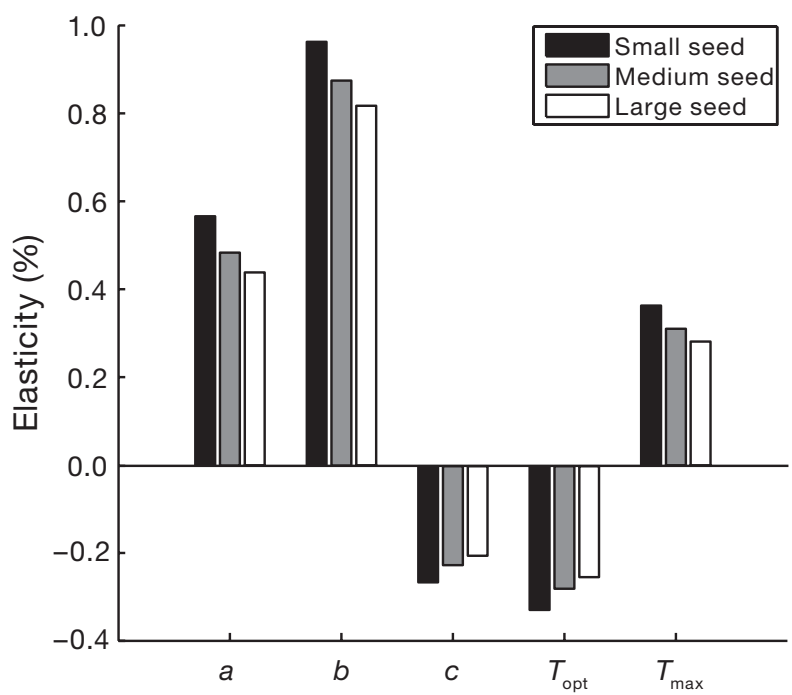

Fig. 6. Mytilus edulis. Elasticity (Eq. 8) of size (mean mussel shell length on a sock) at Day 365 predicted by growth sub-model to a $1 \%$ increase in parameters $a, b, c, T_{\text {opt }}$ or $T_{\max }$ (see Table 1). Initial conditions and temperature are those observed in New London Bay in 2001

dicted by the model is also in accordance with that observed elsewhere (see Bayne 1976 for a review).

\section{Comparisons of predicted and observed data: survival model}

Good agreement was found between the model predictions calibrated with the 2001 data and the observed densities of $2002\left(r^{2}=0.70\right)$ (Fig. 5).

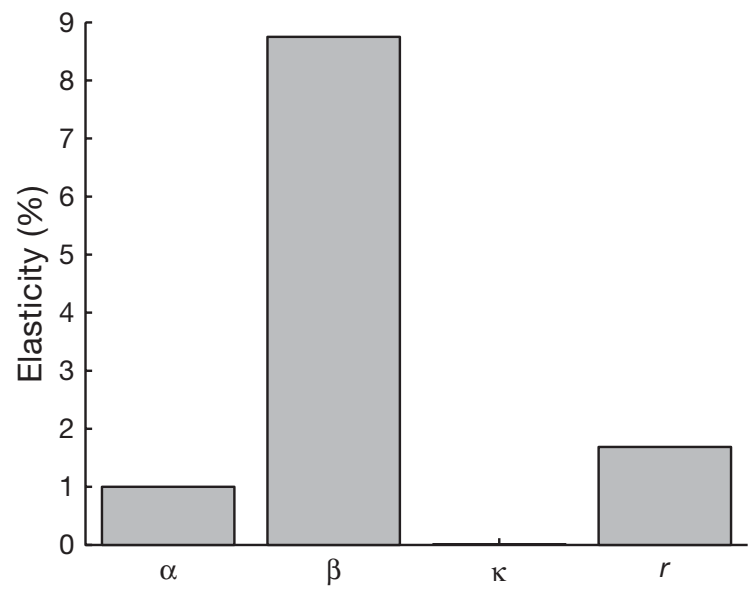

Fig. 7. Mytilus edulis. Elasticity (Eq. 8) of density at harvest predicted by survival sub-model to a $1 \%$ increase in parameters $\alpha, \beta, \kappa$, and $r$ (see Table 1 ). Initial density was set at 350 mussels $30 \mathrm{~cm}^{-1}$ sock

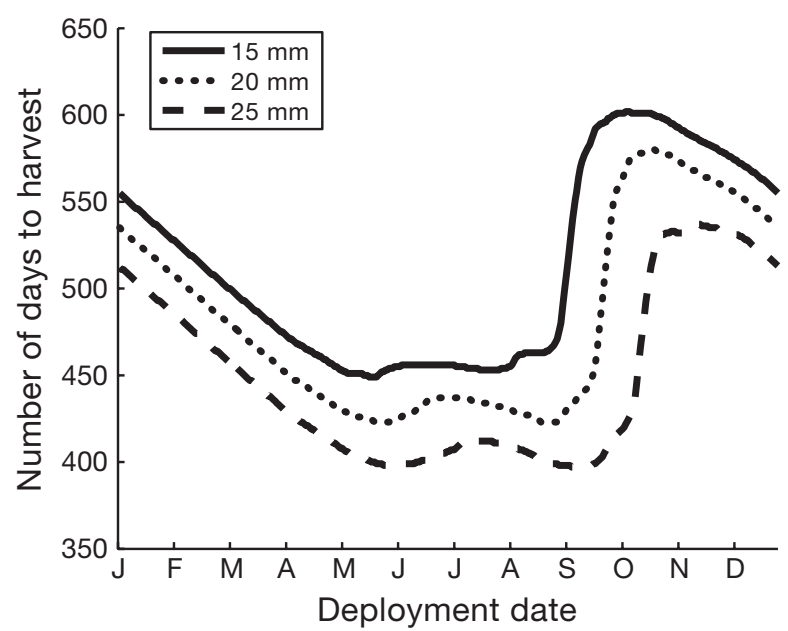

Fig. 8. Mytilus edulis. Seeding time. Prediction from growth sub-model of number of days to reach commercial size (60 mm shell length) for 3 seed sizes of mussels as a function of deployment date

\section{Elasticity analysis}

Elasticity analysis of the growth sub-model indicated that a small change in parameters had a minimal or moderate effect on mussel size at $365 \mathrm{~d}$ (Fig. 6). Increasing the scale parameter for growth (a) by $1 \%$ resulted in an increase $(\sim 0.5 \%)$ in the final predicted size of mussels. The allometric exponent $(b)$ had the strongest effect. Increasing this allometric exponent increased the final predicted size of mussels by reducing the effect of size on mussel growth $(b$ is a negative exponent). A $1 \%$ increase in parameters related to temperature (Eq. 2) had little effect $(<0.5 \%)$ on final 
mussel size. Increasing maximal growing temperature $\left(T_{\max }\right)$ increased final mussel length. In contrast, increasing optimal growing temperature $\left(T_{\text {opt }}\right)$ reduced final mussel length because it increased the difference between observed mean water temperature and optimal growing temperature. Increasing the temperature dependency parameter $(c)$ also resulted in a decrease in final mussel length, since $c$ governs the shape of the temperature relationship and a larger $c$ results in a steeper curve and therefore lower growth rates. Changes in parameters had a slightly greater effect on small than on large seeds.

Elasticity analysis of the survival sub-model indicated that most parameters had a large influence on density at harvest (Fig. 7). Mussel density at harvest was most sensitive to the self-thinning exponent $(\beta)$. A $1 \%$ increase in $\beta$ produced an increase of $>8 \%$ in harvestable density. Increasing $\beta$ decreased the strength of self-thinning ( $\beta$ is a negative exponent) and therefore increased the number of mussels surviving to harvest. A $1 \%$ increase in density at characteristic length $(\alpha)$ and survival rate $(r)$ resulted in increases $(\sim 1$ and $\sim 2 \%$ respectively) of mussel density at harvest. Density at harvest was not sensitive to changes in $\mathrm{K}$ (Fig. 7). Since $\kappa$ controls the rate at which $N$ approaches Nexp and mussels always reach Nexp before reaching harvestable size, any effect of $\kappa$ disappears before harvest.

\section{Evaluation of aquaculture practices}

Only some aspects of mussel aquaculture can be manipulated in an effort to enhance production. Timing of deployment of mussels is one of these. Based on the model, changing the deployment date had a large effect on how quickly mussels reached harvestable size (Fig. 8). If deployment occurs in the summer months, mussels reach harvestable size in 400 to $450 \mathrm{~d}$, whereas if it occurs in the fall, which is the normal practice in PEI, mussels need 550 to $600 \mathrm{~d}$. Changing the seeding time can alter the number of days to reach harvestable size by $33 \%$ for large mussel seed and up to $38 \%$ for small seed.

Aquaculturists may want to maximise the density of mussels at harvest or the proportion of mussels surviving to harvest, both of which are affected by the initial density of seed. Thus, another practice that could be changed is the density at which mussels are socked (Fig. 9). A high number of mussels at harvest can be obtained by using high initial mussel densities (Fig. 9a). Conversely, to obtain a high proportion of mussels surviving to harvest, it is necessary to start with low initial densities because survival decreases with increasing density (Fig. 9b).

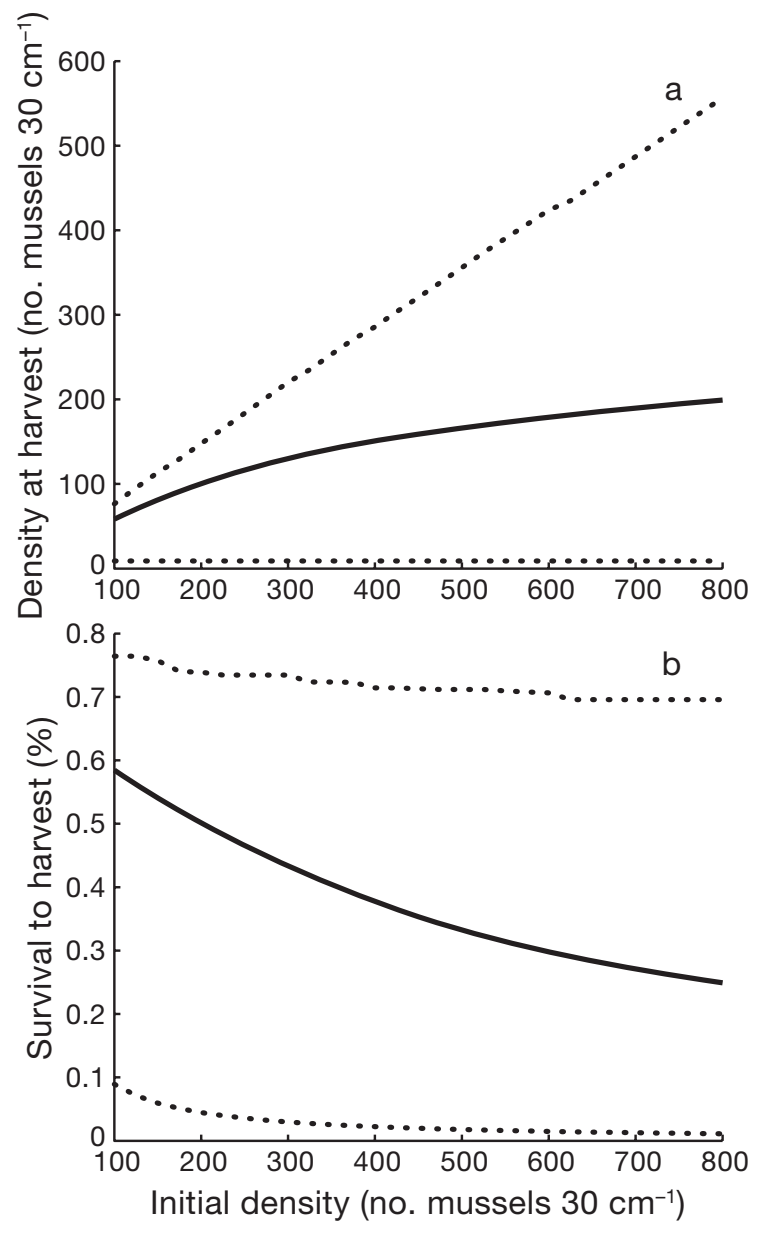

Fig. 9. Mytilus edulis. Socking density. Prediction (continuous line) from survival sub-model of (a) density of mussels remaining on $30 \mathrm{~cm}$ section of sock at harvest, and (b) percentage of mussels surviving on sock until harvest. Dotted lines: $95 \%$ confidence intervals of model prediction

\section{DISCUSSION}

\section{Model formulation and biological insights}

When modelling biological functions, it is essential to use appropriate equations in order to obtain biologically meaningful parameter estimates. For this reason, we elected to use the equation developed by Lassiter \& Kearns (1974) to relate temperature and growth, rather than some of the other more commonly employed relationships (see Cossins \& Bowler 1987). The $Q_{10}$ relationship, which assumes that physiological rates increase exponentially with increasing temperature (for applications see van Haren \& Kooijman 1993, Dowd 1997, and Barbeau \& Caswell 1999), has been widely employed by other investigators. Its formulation is of special interest because it correctly represents, at low temperature, the exponential relationship expected by 
Arrhenius's law (Ursin 1967) between the rate of metabolic processes and temperature. According to Arrhenius's law, enzymatic activity increases following an exponential relationship with temperature. However, it has been demonstrated that $Q_{10}$ values vary with temperature: as temperature increases, the $Q_{10}$ value decreases in a progressive manner (Ege \& Krogh 1914, Krogh 1914). Therefore, using 1 value of $Q_{10}$ over a wide range of temperature (such as experienced in PEI) would overestimate growth at high temperature.

An alternative to the $Q_{10}$ is the use of power functions (Growth $=T^{\text {exponent }}$ ) (Fréchette \& Bacher 1998, Gangnery et al. 2004), which provide a better fit when $Q_{10}$ is known to decrease with increasing temperature. Both formulations $\left(Q_{10}\right.$ and power function) increase indefinitely with increasing temperature, which is bound to overestimate the physiological rates as temperatures go beyond an optimal value. Therefore, although widespread, the usefulness of the $Q_{10}$ relationship or the power function is limited to a narrow range of temperatures. In field situations, especially under circumstances similar to those in PEI, where large variations in water temperature occur throughout the year, Lassiter \& Kearns' (1974) equation, as employed in our model, allows predictions over a greater range of temperatures than more commonly used equations.

Our model and our use of Lassiter \& Kearns' (1974) equation also enabled us to estimate the optimal growing temperature $\left(T_{\text {opt }}\right)$ for mussels. Such estimates are difficult to obtain in the field without the use of a model. In the literature, the optimal growing temperature for Mytilus spp. has been reported to be between 15 and $20^{\circ} \mathrm{C}$ (Coulthard 1929, Coe \& Fox 1942). Furthermore, Mallet \& Carver (1993) observed a decline in shell growth rate in $M$. edulis cultivated in Nova Scotia when the water temperature exceeded $14^{\circ} \mathrm{C}$. Our model estimate for $T_{\text {opt }}\left(15.80 \pm 0.02^{\circ} \mathrm{C}\right)$ is therefore in accordance with these previous observations.

Parameter estimates of the survival sub-model also revealed biological information. For example, $r$ is the survival rate that does not depend on crowding. We obtained a value of 0.999 , which translates into a yearly survival rate of $\sim 81 \%$. This value is in the upper range of survival rates previously found for mussels growing with conspecifics (Mallet \& Carver 1991: 45 to 65\%; Myrand \& Gaudreault 1995: 20 to 90\%). However, in a study looking at survival rate of individual mussels growing on nets (not subject to competition or crowding), Mallet \& Carver (1993) found values (70 to $75 \%$ ) close to our estimate. Because we defined $r$ as the survival rate without density-dependent mortality, it is not surprising that it is higher than survival rates in the presence of competition, but similar to survival rates without competition.
Determining which parameters need to be included in the model gives a good indication of what affects growth and survival of mussels in the field (or, in our case, in an aquaculture situation). Most previous attempts at modelling mussels in an aquaculture setting have used food availability (POM, DOM, chlorophyll $a$ or seston) to predict growth (see Beadman et al. 2002 for review). Our model does not incorporate food availability; seasonal variation in growth is a function of water temperature only. In a similar model applied to Mytilus galloprovincialis, Gangnery et al. (2004) incorporated water temperature in their model to reproduce the observed seasonal variations in growth, and food availability to reproduce the observed spatial variation. In our case, temperature could predict growth in 2 bays over 2 yr without adding any other environmental variable. It therefore appears that either food availability is highly correlated with water temperature in both bays or that food is not a limiting factor for growth in these 2 bays.

Based on our experimental work (Lauzon-Guay et al. 2005) and modelling exercise, survival of cultivated mussels does not vary between sites. Our survival submodel could predict survival at 2 sites. Furthermore, parameter estimates for Eq. (6) did not differ significantly whether the equation was fitted to the 2001 or to the 2002 dataset (J.-S. Lauzon-Guay unpubl. data). Previous studies have also noted that survival of cultivated mussels is not site-dependent (Dickie et al. 1984, Mallet \& Carver 1991, Myrand \& Gaudreault 1995, Karayucel \& Karayucel 2000). This compilation of observations suggests that the mechanisms responsible for self-thinning of mussels in PEI are consistent across years and probably inherent to the mussel population rather than to environmental conditions. This favours space-driven self-thinning over food-driven self-thinning for 2 reasons: (1) as previously mentioned, results from the growth sub-model indicated that food availability was not a factor limiting growth, and (2) competition for space is more likely to be consistent from year to year and site to site than competition for food. Furthermore, the self-thinning exponent obtained in our study is much closer to the value expected from space-driven self-thinning than fooddriven self-thinning (Fréchette \& Lefaivre 1990).

Uncertainty associated with our growth predictions was relatively small, which is somewhat surprising given the usual high level of individual variation (up to 10 times) in growth observed in mussels (Mallet \& Carver 1991, Trevelyan 1991). Our relatively small level of uncertainty is probably due to 3 reasons. First, our confidence intervals around mussel size predictions represent variation in mean size of mussels on socks and do not represent variation in size of individual mussels (i.e. we used the model to simulate our 
large-scale experiments, and the experimental unit in these experiments was mussel sock and not individual mussel). Second, a high number of marked mussels was monitored for growth in the small-scale experiments, and this highlights the importance of developing an adequate sampling protocol when gathering data for model calibration.. Finally, the fact that our growth model was fairly robust (Fig. 6) helped attenuate the effect of sampling error on the model output. Conversely, the survival model was quite sensitive. This sensitivity and the large standard error associated with parameter estimates resulted in high uncertainty in survival predictions (Fig. 9). This level of uncertainty was expected given the general high variability in mussel survival (Dickie et al. 1984, Mallet et al. 1990, Myrand \& Gaudreault 1995). In addition, some of the variability is likely to have stemmed from the difficulty in obtaining consistent initial densities of mussels between socks (Lauzon-Guay et al. 2005). Consequently, it was difficult to estimate survival precisely. Therefore, experimental work with better controlled initial densities of mussels would be necessary to improve survival estimates. Also, including size-specific mortality, asymmetric competition, and inter-individual variability in growth in our models may have affected our mussel survival predictions (Fréchette et al. 2005) and may prove to be a valuable avenue for future modelling work.

The results of the sensitivity analysis provided additional insights on potentially important processes affecting populations of cultivated mussels. Our growth predictions were robust to changes in the allometric exponent $(b)$, density at characteristic length $(a)$, optimal growing temperature $\left(T_{\text {opt }}\right)$, maximal growing temperature $\left(T_{\max }\right)$, and strength of the temperature dependency $(c)$. In other words, relatively large changes in the relationship between growth and its underlying variables would be necessary to result in appreciable changes in mussel production. Conversely, survival predictions were quite sensitive to changes in most parameters, namely the coefficient for density dependence $(\alpha)$, the survival rate $(r)$, and especially the self-thinning exponent $(\beta)$. Thus, intraspecific competition between mussels appears to be a particularly important process affecting their survival. Future research should focus on improving our understanding of intraspecific competition and the self-thinning relationship in mussels.

\section{Aquaculture implications}

It may be possible to increase mussel production through optimization of growth rates by adjusting the deployment date of socks. If seeds were packed in socks between May and September, aquaculturists might be able to reduce the grow-out period by up to $35 \%$. Most of the socking actually occurs between October and December on PEI (Mallet \& Myrand 1995). Based on our modelling exercise, this results in the longest turnaround time for seeds to reach commercial size.

However, although our results suggest that it may be advantageous to alter socking time, this may prove impractical for other reasons. For example, mussel seed of an appropriate size may not be available in summer, and deployment of mussels during warm summer conditions may increase stress and mortality of mussels during socking. Further, development of a socking strategy to maximise profits should also involve consideration of timing of seeding and harvest such that a lag between crops is minimized (see Melià \& Gatto 2005 for example). Nonetheless, aquaculturists should consider deploying mussels earlier in the fall (September), as this would still result in a substantial reduction of the grow-out period. Overall, this strategy may be beneficial, even if it entails using smaller seeds (as long as they are not socked too densely). Smaller seeds have been observed to reach commercial size in the same time period as large seeds, because of their faster growth rates (Lauzon-Guay et al. 2005). Meanwhile, further research should be done to evaluate possible changes in survival resulting from deploying mussels in the summer.

Socking density (i.e. no. of mussels sock ${ }^{-1}$ ) clearly plays an important role in the survival of mussels to commercial size. According to model predictions, 2 options are available to aquaculturists: (1) maximise the proportion of mussels surviving to harvest and (2) maximise the number of mussels per sock available at harvest. These 2 strategies are mutually exclusive, because survival is maximised using low initial density, and number of mussels at harvest is maximised using high initial density. The best approach to take would depend on whether lease area or mussel seed availability was more limiting. A shortage of seeds would dictate that aquaculturists should pack seeds at low initial density, although this could increase labourrelated costs. Conversely, if seeds are abundant but space is the limiting factor, an aquaculturist should use high initial density to assure a greater number of mussels at harvest. However, it is likely that beyond a certain initial density, density at harvest will remain constant (Lauzon-Guay et al. 2005). In PEI, seed shortage has occurred periodically in the past; in such years, using low initial density would insure a greater yield. On the other hand, as availability of lease area becomes more limited, mussel aquaculturists may want to use higher initial densities, especially in years when seeds are abundant. 


\section{CONCLUSION}

Simple mathematical models of population dynamics that incorporate individual-based processes coupled with mechanisms at the population level can produce accurate predictions. Our results suggest that at our 2 sites, growth of suspended mussels can be modelled using allometric growth coupled with water temperature as the only environmental factor. Our model requires few variables to be measured in the field, which facilitates its use in more locations. However, such a model would probably not be applicable to situations where food availability is low.

Our model proved useful in assessing different short-term management scenarios (over 1 grow-out cycle). By socking in summer or early autumn, aquaculturists could reduce their turnaround time by up to $35 \%$ compared to socking in mid- to late-autumn. Also, depending on specific situations, an aquaculturist could increase mussel survival by using low initial densities, or increase the number of mussels available at harvest by using high initial densities. In sum, this modelling exercise has enhanced our understanding of mechanisms responsible for population dynamics of cultivated mussels, enabled evaluation of possible management scenarios, and offered direction for further research.

Mussel survival can be predicted as a function of the size of mussels and their initial density using a selfthinning relationship. The relationship between survival and shell length remained constant over $2 \mathrm{yr}$ at 2 sites, suggesting that survival is not related to sitespecific environmental conditions. More research is necessary to fully understand the mechanisms responsible for self-thinning. Such information could then be used to alleviate density-dependent survival and to increase production.

Acknowledgements. We thank M. Dionne, T. McMullen, A. Simmonds, A. Sprague, J. Mainguy, E. Phillips, M. Wong, A. Tam and T. Marshall for their help, patience and resilience in collecting and processing mussel samples; S. Stewart of Stewart Mussels Farm, R. Fortune of United Mussels Farm and their crews for their invaluable help; Prince Edward Island Department of Fisheries, Aquaculture and Environment for their assistance and use of equipment and facilities; PEI Aquaculture Alliance for supplying mussel seed and logistic support; and R. Rochette and ACWERN (Atlantic Cooperative Wildlife Ecology Research Network) for lending us equipment. We are also grateful to A. Gangnery for helpful discussions and 2 anonymous reviewers for critical comments on this manuscript. This research was supported by funds from AquaNet (the Network of Centres of Excellence for Aquaculture in Canada) (M.A.B.) and the Canadian Wildlife Service (D.J.H.). Additional funding was provided by the Natural Sciences and Engineering Research Council of Canada (PGS award to J.S.L.G. and PDF award to D.J.H), a Vaughan Graduate Fellowship in Marine Sciences (J.-S.L.-G.), the Network of Centres of Excellence for Mathematics of Information Technology and Complex Systems (MITACS; J.W.), and the Department of Biology, University of New Brunswick.

\section{LITERATURE CITED}

Almada-Villela PC, Davenport J, Gruffydd LLD (1982) The effects of temperature on the shell growth of young Mytilus edulis L. J Exp Mar Biol Ecol 59:275-288

Barbeau MA, Caswell H (1999) A matrix model for short-term dynamics of seeded populations of sea scallops. Ecol Appl 9:266-287

Bayne BL (1976) Marine mussels: their ecology and physiology. Cambridge University Press, Cambridge

Beadman HA, Willows RI, Kaiser MJ (2002) Potential applications of mussel modelling. Helgol Mar Res 56:76-85

Caswell H (2001) Matrix population models, 2nd edn. Sinauer Associates, Sunderland, MA

Coe WR, Fox DL (1942) Biology of the Californian sea mussel Mytilus caifornianus. I. Influence of temperature, food supply, sex and age on the rate of growth. J Exp Zool 90: $1-30$

Conway GR (1977) Mathematical models in applied ecology. Nature 269:291-297

Cossins AR, Bowler K (1987) Temperature biology of animals. Chapman \& Hall, London

Coulthard HS (1929) Growth of the sea mussel. Contrib Can Biol Fish 4:123-136

Dickie LM, Boudreau PR, Freeman KR (1984) Influences of stock and site on growth and mortality in the blue mussel (Mytilus edulis). Can J Fish Aquat Sci 41:134-140

Dowd M (1997) On predicting the growth of cultured bivalves. Ecol Model 104:113-131

Ege R, Krogh A (1914) On the relation between temperature and the respiratory exchanges in fishes. Int Rev Gesamten Hydrobiol 7:48-55

Evans M, Hastings N, Peacock B (2000) Statistical distributions, 3rd edn. John Wiley \& Sons, New York

Fréchette M, Bacher C (1998) A modelling study of optimal stocking density of mussel populations kept in experimental tanks. J Exp Mar Biol Ecol 219:241-255

Fréchette M, Lefaivre D (1990) Discriminating between food and space limitation in benthic suspension feeders using self-thinning relationships. Mar Ecol Prog Ser 65:15-23

Fréchette M, Aitken AE, Page L (1992) Interdependence of food and space limitation of a benthic suspension feeder: consequences for self-thinning relationships. Mar Ecol Prog Ser 83:55-62

Fréchette M, Bergeron P, Gagnon P (1996) On the use of selfthinning relationships in stocking experiments. Aquaculture 145:91-112

Fréchette M, Alunno-Bruscia M, Dumais JF, Sirois R, Daigle G (2005) Incompleteness and statistical uncertainty in competition/stocking experiments. Aquaculture 246: 209-225

Gangnery A, Chabirand JM, Lagarde F, Le Gall P, Oheix J, Bacher C, Buestel D (2003) Growth model of the Pacific oyster, Crassostrea gigas, cultured in Thau lagoon (Méditerranée, France). Aquaculture 215:267-290

Gangnery A, Bacher C, Buestel D (2004) Application of a population dynamics model to the Mediterranean mussel, Mytilus galloprovincialis, reared in Thau Lagoon (France). Aquaculture 229:289-313

Gosling E (ed) (1992) The mussel Mytilus: ecology, physiology, genetics and culture. Developments in aquaculture and fisheries science, Vol 25. Elsevier, Amsterdam 
Goss-Custard JD, Caldow RWG, Clarke RT, West AD (1995) Deriving population parameters from individual variations in foraging behaviour. 2. Model tests and population parameters. J Anim Ecol 64:277-289

Hilgerloh G, Siemoneit H (1999) A simple mathematical model upon the effect of predation by birds on a blue mussel (Mytilus edulis) population. Ecol Model 124:175-182

Hughes RN, Griffiths CL (1988) Self-thinning in brnacles and mussels: the geometry of packing. Am Nat 132:484-491

Karayucel S, Karayucel I (2000) Influence of stock and site on growth, mortality and shell morphology in cultivated blue mussels (Mytilus edulis L.) in two Scottish sea lochs. Isr J Aquacult Bamidgeh 52:98-110

Krogh A (1914) The quantitative relation between temperature and standard metabolism in animals. Int Z PhysChem Biol 1:491-508

Lassiter RR (1975) Modeling dynamics of biological and chemical components of aquatic ecosystems. US Environmental Protection Agency, Office of Research and Development, National Environmental Research Center, Corvallis, OR, EPA-660/3-75-012

Lassiter RR, Kearns DK (1974) Phytoplankton population changes and nutrient fluctuations in a simple aquatic ecosystem model. In: Middlebrookers EJ, Falkenberger DH, Maloney TE (eds) Modelling the eutrophication process. Ann Arbour Science, Ann Arbor, MI, p 131-188

Lauzon-Guay JS, Barbeau MA, Hamilton DJ (2005) Effects of seed size and density on growth, tissue-to-shell ratio and survival of cultivated mussels (Mytilus edulis) in Prince Edward Island, Canada. Aquaculture 250:652-665

Mallet AL, Carver CE (1991) An assessment of strategies for growing mussels in suspended culture. J Shellfish Res 10: 471-477

Mallet AL, Carver CE (1993) Temporal production patterns in various size groups of the blue mussel. J Exp Mar Biol Ecol 170:75-89

Mallet AL, Myrand B (1995) The culture of the blue mussel

Editorial responsibility: Otto Kinne (Editor-in-Chief), Oldendorf/Luhe, Germany in Atlantic Canada. In: Boghen AD (ed) Cold-water aquaculture in Atlantic Canada. The Canadian Institute for Research on Regional Development, Moncton, p 255-296

Mallet AL, Carver CE, Freeman KR (1990) Summer mortality of the blue mussel in eastern Canada: spatial, temporal, stock and age variation. Mar Ecol Prog Ser 67:35-41

Manly BFJ (1997) Randomization, bootstrap and Monte Carlo methods in biology, 2nd edn. Chapman \& Hall/CRC, New York

Mathews JH, Fink KD (2004) Numerical methods using Matlab, 4th edn. Pearson Prentice Hall, Upper Saddle River, NY

Melià P, Gatto M (2005) A stochastic bioeconomic model for the management of clam farming. Ecol Model 184: 163-174

Myrand B, Gaudreault J (1995) Summer mortality of blue mussels (Mytilus edulis Linneaus, 1758) in the Magdalen Islands (southern Gulf of St. Lawrence, Canada). J Shellfish Res 14:395-404

Read KRH, Cumming KB (1967) Thermal tolerance of the bivalve molluscs Modiolus modiolus (L.), Mytilus edulis (L.) and Brachidontes demissus (Dillwyn). Comp Biochem Physiol 22:149-155

Solidoro C, Pastres R, Melaku Canu D, Pellizzato M, Rossi R (2000) Modelling the growth of Tapes philippinarum in Northern Adriatic lagoons. Mar Ecol Prog Ser 199: 137-148

Trevelyan GA (1991) Aquaculture ecology of hatchery-reproduced juvenile bay mussels, Mytilus edulis L. PhD dissertation, University of California, Davis, CA

Ursin E (1967) A mathematical model of some aspects of fish growth, respiration, and mortality. J Fish Res Board Can 24: $2355-2453$

van Haren RJF, Kooijman SALM (1993) Application of a dynamic energy budget model to Mytilus edulis (L.). Neth J Sea Res 31:119-133

Westoby M (1984) The self-thinning rule. Adv Ecol Res 14: $167-225$

Submitted: March 23, 2005; Accepted: January 10, 2006

Proofs received from author(s): September 19, 2006 